\title{
Effectiveness of Hallux Valgus Surgery on Improving Health- related Quality of Life: A Follow Up Study
}

\section{Luis Enrique Hernández-Castillejo \\ Universidad de Castilla-La Mancha https://orcid.org/0000-0003-3900-9443}

Vicente Martínez-Vizcaíno

Universidad de Castilla-La Mancha

Celia Alvarez-Bueno ( $\sim$ Celia.AlvarezBueno@uclm.es)

Health and Social Research Center, Universidad de Castilla La Mancha, Cuenca, Spain. https://orcid.org/0000-0002-6176-

1618

José Luis Quijada-Rodríguez

Hospital General Virgen de la Luz: Hospital Virgen de la Luz

Miguel Alonso-Galán

Hospital Virgen de la Luz

Miriam Garrido-Miguel

Universidad de Castilla-La Mancha

Research

Keywords: Quality of life, hallux valgus, PROMs, surgery

Posted Date: December 31st, 2020

DOI: https://doi.org/10.21203/rs.3.rs-136126/v1

License: (c) (i) This work is licensed under a Creative Commons Attribution 4.0 International License. Read Full License 


\section{Abstract}

\section{Background}

Hallus valgus (HV) negatively impacts health-related quality of life (HRQoL). Patient-reported outcome measures (PROMs) are increasingly used in clinical studies of the foot and ankle. We aimed to evaluate the effect of HV surgery on PROMs (i.e., pain scales, general HRQoL, and region-specific scales) and radiological angles. Additionally, we aimed to determine whether the effect on these outcomes depends on the type of surgery (including open and percutaneous techniques) and if it is influenced by potential confounding factors (i.e., age, HVA, 1-2 IMA, body mass index (BMI), and distal metatarsal articular angle (DMAA).

Methods

This was a longitudinal prospective study. We collected the clinical data of all patients who underwent surgery for symptomatic HV deformity in the orthopedic department of the Virgen de la Luz Hospital of Cuenca (Spain). The clinical outcomes were assessed using the American Orthopedic Foot and Ankle Society (AOFAS) Hallux metatarsophalangealinterphalangeal (HMI) scale, visual analogue scale (VAS), Manchester Oxford foot questionnaire (MOXFQ), short form health survey (SF-12) and European Quality of Life-5 Dimensions (EQ-5D).

Results

A total of 72 patients (70 women, $97.2 \%$ ) were included in the study 72 (72 feet). The AOFAS pre-post-surgery score changed from 42.16 (SD: 10.11) to 83.31 (SD: 6.23). Considering AOFAS domains, the pre-post change was from 14.17 (SD: 9.15$)$ to 33.19 (SD: 4.69) for pain, from 27.22 (SD: 3.90) to 37.94 (SD: 2.78) for function, and from 0.78 (SD: 2.38) to 12.18 (SD: 3.45 ) for alignment. For other clinical outcomes was VAS score from 5.01(SD: 1.26) to 1.26 (SD: 0.96) and MOXFQ score from 61.44 (SD: 7.09) to 12.35 (SD: 4.85). SF-12 (physical) changed from 36.26 (SD: 5.32) to 47.06 (SD: 4.82), SF-12 (mental) from 38.23 (SD: 8.04) to 46.49 (SD: 4.16), and EQ5-D from 0.64 (SD: 0.008) to 0.90 (SD: 0.10).

Conclusions

Our data confirmed the improvements in the clinical and radiological outcomes after HV surgery, and provided some evidence of these improvements not depending on the type of surgery or on some potential confounding factors such as BMI, HVA, 1-2 IMA, and DMAA.

\section{Introduction}

Hallux valgus $(\mathrm{HV})$ is a frequent pathological disorder of the forefoot ${ }^{1}$ that commonly produces painful disability. $\mathrm{HV}$ is used to describe the structural deformity of the first metatarsophalangeal joint (MTPJ), ${ }^{2,3}$ clinically determined when the HV angle is greater than $15^{\circ}$ and the 1-2 intermetatarsal angle (IMA) is greater than $9{ }^{\circ} .{ }^{4}$ Although $\mathrm{HV}$ has a clear genetic component, being predominant amongst women, ${ }^{5}$ it is a progressive deformity, especially in those aged over 50 years. The prevalence of $\mathrm{HV}$ increases from $23 \%$ in adults aged 18 to 65 years to $35.7 \%$ in people aged over 65 years. ${ }^{6,7}$

As a result of both pain and disability, HV deformity negatively impacts the health-related quality of life (HRQoL). ${ }^{8,9}$ The greater the HV angle and first finger pain, the worse the scores in the physical, psychological, and social aspects of HRQoL. ${ }^{10,11}$ It has been determined ${ }^{12}$ that HV deformity is coupled with significant foot-specific pain and disability, even when global physical functioning and participation in activities are not adversely affected. Over time, as severity of HV deformity increases, progressive muscle weakness occurs around the first MTPJ and both general and foot-specific HRQoL scoring progressively decrease. ${ }^{10,13}$

Numerous surgical procedures have been developed for the treatment of HV. ${ }^{14}$ However, no consensus exists on the optimal surgical technique to correct this deformity. ${ }^{15,16}$ Thus, the surgical choice should be taken after considering the range of 
causal factors. ${ }^{17,18,19}$ Open procedures are the most commonly used surgical techniques, including chevron's distal osteotomy and scarf's diaphyseal in the first metatarsal. ${ }^{20,21,22}$ In the last years, the interest in minimally invasive surgery (MIS) has been growing due to its theoretical advantages including lower morbidity and less time required for recovery and rehabilitation. ${ }^{23}$ However, the evidence supporting percutaneous techniques is still inconclusive ${ }^{24,25}$ per randomized control trials with designed treatment protocols and the use of validated tools for measurements.

Most studies ${ }^{26-28}$ have reported improvements on the correction of the radiological angles (HVA and 1-2 IMA) as well as in HRQoL assessed by the American Orthopedic Foot and Ankle Society (AOFAS) scale. Although the AOFAS score cannot be considered a true patient-reported outcome measures $(\mathrm{PROM})^{29}$, it is usually the most used tool in clinical studies of the foot and ankle. ${ }^{30,31}$ Systematic reviews ${ }^{32}$ have shown that $\mathrm{HV}$ surgery is a more effective procedure than conservative or no treatment in reducing pain ${ }^{33}$. However, high-quality studies comparing similar types of HV treatments and rates of complications or unfavorable outcomes re lacking. ${ }^{34}$

Thus, we aimed to evaluate the effect of HV surgery on PROMs (i.e., pain scales, general HRQoL, and region-specific scales) and radiological angles. Additionally, we aimed to determine whether the effect on these outcomes depends on the type of surgery (including open and percutaneous techniques) and if it is influenced by potential confounding factors (i.e., age, HVA, 1-2 IMA, body mass index (BMI), and distal metatarsal articular angle (DMAA).

\section{Methods}

\section{Study Design}

This was a longitudinal prospective study conducted between March 2017 and May 2018. The study was designed and conducted in accordance with the Declaration of Helsinki and the Guidelines on Good Clinical Practice, ${ }^{35}$ and was approved by the Clinical Research Ethics Committee of the Cuenca Health Area. Written and oral informed consent was obtained from all participants.

We collected the clinical data of all patients who underwent surgery for symptomatic HV deformity in the orthopedic department of the Virgen de la LuH Hospital of Cuenca (Spain). All surgical techniques were performed by orthopedists and included open surgery (chevron osteotomy ${ }^{36}$ and scarf osteotomy ${ }^{37}$ ) and percutaneous surgery with Reverdin-Isham osteotomy. ${ }^{38}$

The inclusion criteria for patients were (1) older than 18 years with painful HV; (2) complete conservative treatment (including oral medication, shoe modification, and physical therapy for three months); (3) mild-to-moderate HV deformity ${ }^{39}$, a preoperative HVA $<40^{\circ}$ and $1-2 \mathrm{IMA}<20^{\circ}$; (4) primary HV surgery, and (5) signed written informed consent. We excluded patients with severe hallux rigidus (radiological suggestion of severe degenerative arthritis) of MTPJ or stiffness, severe instability of the first tarsometatarsal joint, previous failed HV surgery, infection, peripheral vascular disease, peripheral neuropathy or other systemic diseases affecting the musculoskeletal system, and patients with a follow-up of $<12$ months.

A total of 81 eligible patients were initially included in our study, but 9 patients were lost to follow-up. The type of osteotomy was decided according to the HVA, the 1-2 IMA, and the surgeon's opinion. Chevron osteotomy was conducted in 16 patients (16 feet), scarf osteotomy was performed in 24 patients (24 feet) ,and percutaneous surgery was completed in 32 patients (32 feet). Akin osteotomy ${ }^{40}$ was performed in 22 patients ( $\left.22 \mathrm{feet}\right)(30 \%)$ of the total.

\section{Clinical outcomes}

The clinical outcomes were assessed using the AOFAS Hallux metatarsophalangeal-interphalangeal (HMI) scale ${ }^{41}$, visual analogue scale (VAS) ${ }^{42}$, Manchester-Oxford Foot Questionnaire (MOXFQ) ${ }^{43}$, short form health survey $\left(\right.$ SF-12) ${ }^{44}$, and 
European Quality of Life-5 Dimensions (EQ-5D). ${ }^{45}$ These outcomes were evaluated before surgery and at the end of the followup; additionally, the post-operative complications were recorded at end of follow-up.

The AOFAS-HMI scale (range, $0-100$ best score) recording system combines subjective and objective data to assess the following clinical factors: pain (40 points), function (45 points), and alignment (15 points). ${ }^{46}$ The VAS consists of a straight line with the endpoints scoring 0 (no pain at all) to 10 (the worst pain imaginable). The MOXFQ is a patient-based questionnaire for assessing HRQoL in patients receiving foot and/or ankle surgery. It consists of a 16-item summative Likert scale scored from 0 to 4 (most severe) in three dimensions: pain, walking/standing, and social interaction. The total score ranges from 0 to 64 . The MOXFQ index is calculated as the percentage of the maximum score dividing the total score by the maximum possible score (i.e., 64 ) and multiplied by 100.47

The SF-12 questionnaire is a 12-item survey including physical and mental health components (PCS-12 and MCS-12) ${ }^{48}$ EQ$5 \mathrm{D}^{49}$ includes 5 questions about the patients' mobility, self-care, usual activities, pain/discomfort, and anxiety/depression. The total score ranges from 1 (without problems) to 5 (unable to perform/extreme problems).

\section{Radiological assessment}

The radiological examination of HVA, 1-2 IMA and DMAA, was completed by the same independent observer and according to the same radiographic protocol. Weight-bearing dorsoplantar and lateral images were obtained preoperatively, immediately after the surgery, and at the end of the follow-up. ${ }^{50}$ The HVA is measured using the anteroposterior view as the angle between the line connecting the center of the first metatarsal base and the metatarsal head with the line connecting the center of the proximal and distal articular surfaces of the proximal phalanx. The 1-2 IMA is measured as the angle between the former line and the line bisecting the diaphyseal portion of the second metatarsal. Finally, the DMAA is defined as the angle between the perpendicular line and the longitudinal axis of the first metatarsal. ${ }^{51,52}$

\section{Surgery procedures}

The surgical procedures were completed using local or block anesthesia in the supine position and under tourniquet control. During surgery, the foot was kept externally rotated with its lateral edge on the operating table.

The distal metatarsal chevron osteotomy ${ }^{36}$ was completed through a medial incision starting from the proximal phalanx medially, continuing proximally beside the medial margin of the metatarsal; a longitudinal midline capsulotomy was performed in the identical plane as the incision. The apex of the osteotomy was positioned 1-2 mm superior to the center of the metatarsal head and the angle of the chevron was $60^{\circ}$ to $90^{\circ}$. Fixation was achieved by two cannulated screws.

Scarf osteotomy ${ }^{37}$ was performed with a skin lateral incision of $3-4 \mathrm{~cm}$ and a longitudinal capsular incision. The longitudinal osteotomy was oblique from the longitudinal axis of the first metatarsal and the transverse limbs ought to be parallel to each other, perpendicular to the second metatarsal, and approximately $60^{\circ}$ to $80^{\circ}$ positioned to the longitudinal osteotomy line. Fixation was achieved with a two headless compression screws.

The adductor hallucis tendon section and a lateral soft tissue release were completed in all cases for both techniques and an intraoperative observation for DMAA was performed. The hallux was then reduced to a neutral position and congruency of the MTPJ was confirmed under fluoroscopy.

Otherwise, percutaneous surgery was performed through a 3-5 mm skin incision on the medial and plantar side of the first metatarsal head. The exostosectomy was removed from this incision with a conical burr. Reverdin-Isham osteotomy ${ }^{23,38}$ was performed using a Shannon straight burr. Finally, we completed a lateral soft tissue release of the MTPJ and a tenotomy of the adductor hallucis tendon through a 1-2 mm skin incision. All steps were verified under fluoroscopy. Osteosynthesis was not used in any case of percutaneous surgery. The Akin osteotomy ${ }^{40}$ of the proximal phalanx was chosen for the existence of interphalangeus. The Akin osteotomy was performed without osteosynthesis. 
The sample size was estimated considering a pre-post-surgery difference of $2.5 \%$ (a error 0.05 ; statistical power of 0.80 ) in AOFAS scale mean score, obtaining a minimal estimated sample size of 43 patients. To have sufficient statistical power for examining other outcomes and estimating a 15\% dropout rate, the minimum sample size was estimated on 72 patients.

Both statistical (Kolmogorov-Smirnov test) and graphical methods (normal probability plots) were used to assess the normal distribution for each continuous variable. In the descriptive statistics section, categorical variables are presented as sample ( $n$ ) and percentage (\%), and continuous variables are presented as mean and standard deviation (SD). Repeated measures ANCOVA models were used to test the mean differences of the pre-post-surgery clinical and radiological outcomes, adjusted by baseline values of clinical outcomes (i.e., VAS, MOXFQ, SF-12, and EQ-5D) in Model 1, and adjusted by baseline values, age, BMI, HVA, 1-2 intermetatarsal angle, and distal metatarsal articular in Model 2. We estimated the crude change and the effect size (ES) for each outcome using Cohen's d index. ${ }^{53}$ The ES was categorized as 0.2 (weak effect), 0.5 (moderate effect), 0.8 (strong effect), and $>1.0$ (very strong effect). Additionally, Student's t-test and ANOVA were used to test mean differences in

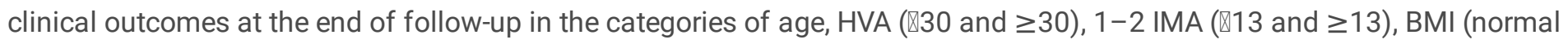
weight, overweight, and obesity), and DMAA. Statistical analyses were performed using SPSS-IBM (V.24.0 SPSS Inc., Armonk, NY, USA), and statistical significance was set at $p \leq 0.05$.

\section{Results}

\section{Characteristics of the case series}

The final number of patients included in the study was 72 (72 feet), mean age 59.67 years (SD: 11.39) and including 70 women (97.2\%). Each patient was followed for at least 12 months with a total mean follow-up period of 17.68 months (SD: 3.11 months). Demographic baseline characteristics are summarized in Table 1.

\section{Clinical and radiological outcomes.}

For the total sample, AOFAS pre-post-surgery score changed from 42.16 (SD: 10.11) to 83.31 (SD: 6.23). Considering AOFAS domains, the pre-post change was from 14.17 (SD: 9.15) to 33.19 (SD: 4.69) for pain, from 27.22 (SD: 3.90) to 37.94 (SD: 2.78) for function, and from 0.78 (SD: 2.38) to 12.18 (SD: 3.45) for alignment. The pre-post-surgery change for other clinical outcomes was: VAS score from 5.01 (SD: 1.26) to 1.26 (SD: 0.96) and MOXFQ score from 61.44 (SD: 7.09) to 12.35 (SD: 4.85 ). In relation to general QoL PROMs, SF-12 (PCS) changed from 36.26 (SD: 5.32) to 47.06 (SD: 4.82), SF-12 (MCS) from 38.23 (SD: 8.04) to 46.49 (SD: 4.16), and EQ5-D from 0.64 (SD: 0.008) to 0.90 (SD: 0.10) (Table 2).

The pre-post-surgery change in the radiographic measurements included: HVA from $30.8^{\circ}$ (SD: $\left.3.56^{\circ}\right)$ to $10.22^{\circ}\left(\mathrm{SD}: 1^{\circ} .01^{\circ}\right)$, 1-2 IMA from $12.31^{\circ}\left(\mathrm{SD}: 1.60^{\circ}\right)$ to $7.71^{\circ}\left(\mathrm{SD}: 0.86^{\circ}\right)$, and DMAA from $13.44^{\circ}$ (SD: $\left.0.88^{\circ}\right)$ to $7.55^{\circ}\left(\mathrm{SD}: 0.99^{\circ}\right)$ (Table 2).

Non-significant differences were found in clinical outcomes at the end of the follow-up by type of surgery except for the PCS12 between scarf osteotomy and percutaneous surgery $(p=0.006)$. Regarding the angles, greater improvements in the $1-2$ IMA were found for chevron osteotomy versus scarf osteotomy, chevron osteotomy versus percutaneous surgery, and scarf osteotomy and percutaneous $(p=0.001)$. In addition, better improvements in DMAA were found for chevron versus scarf osteotomy, chevron osteotomy versus percutaneous surgery, and scarf osteotomy versus percutaneous $(p=0.001$; Supplementary Material Table S1). Finally, after controlling for baseline clinical outcomes (model 1), as well as for baseline clinical outcomes, age, BMI, HVA, 1-2 IMA, and DMAA, the differences in clinical and radiological outcomes were not substantially modified (Tables 3 and 4 ).

Overall, no differences were found when we analyzed the mean of the clinical outcomes at the end of follow-up by categories of HVA, 1-2 IMA, age and BMI. (Supplementary material table S2)

\section{Complications}


At the end of follow-up, a total of seven complications occurred in six patients (six feet) (8.4\%). There were two patients suffering transfer metatarsalgia, three patients with recurrent asymptomatic HV, one patient had first MTPJ stiffness, and another patient had complex regional pain syndrome type 1. One patient suffered metatarsalgia and recurrent asymptomatic HV simultaneously. No patient suffered head necrosis or troughing, ${ }^{54}$ failure of fixation, delayed wound healing, or Varus deformity.

\section{Discussion}

This follow up study was aimed to examine the effect of HV surgery on PROMs (i.e., pain scales, general HRQoL, and regionspecific scales) and radiological angles, and to determine whether the observed effects could be modified by the type of surgery (including open and percutaneous techniques) and by confounding factors. Our data indicated that HV surgery improves patients' PROMs and radiological angles regardless the type of surgery. These effects persist after controlling for potential confounders (i.e., age, HVA, 1-2 IMA, BMI, and DMAA).

We found pre-post improvements in the VAS, AOFAS (total score and specific domains), MOXFQ (total score and specific domains), PCS and MCS of SF-12, and EQ-5D scores, similar to findings reported in previous studies. ${ }^{55,56,57}$ Although most studies only reported data from the AOFAS and VAS scales, the use of PROMs ${ }^{58}$ is encouraged to assess HV surgery outcomes. ${ }^{59}$ Their inclusion could provide valuable information for the evaluation of patients' outcomes, ${ }^{33}$ and could play an important role in determining the impact of HV surgery on HRQoL.

The correction of radiological angles is related to improvement in PROMs, ${ }^{29}$ although we observed a correction in the angles and poor scores in the PROMs, especially in the pain scoring. From this perspective, our data showed improvements after surgery in the three radiological angles (i.e., HVA, 1-2 IMA, and DMAA) similar to those previously reported in other studies. ${ }^{60,61}$

When we analyzed whether the observed effects on clinical outcomes could be modified by the type of surgery and confounding factors, we did not find substantial differences in the results after adjusting for different sets of confounders. The differences found in the 1-2 IMA and DMAA angles between types of surgery may be due to the surgeon's decision based on the initial angles. Additionally, the role of BMI in HV surgery outcomes has been previously studied, ${ }^{62,63}$ and BMI did not act as a predictor for functional outcomes; thus, patients with obesity should not be excluded from HV surgery. ${ }^{64}$

The overall complication rate in our study was $8.4 \%$. Although these figures are slightly higher than those reported by other studies, ${ }^{65,66,67}$ our complication rate is acceptable, considering the surgical variability and the lack of appearance of serious complications. Additionally, recurrence is a feared complication after HV surgery, with rates ranging from $3 \%$ to $73 \%$, $61,63,68,69$ being $4.2 \%$ in our study. HV recurrence has been correlated with preoperative HVA, 1-2 IMA, and DMAA. ${ }^{70,71,72}$ Preoperative HVA has been considered the most important predictor of outcomes after HV surgery, with 1-2 IMA and DMAA playing secondary roles in postoperative outcomes. We found an acceptable recurrence rate for the three surgical techniques and found no differences between them. ${ }^{73}$

There are some limitations to this study that should be acknowledged. First, the follow-up period was relatively short for evaluating long-term HV recurrence. Second, the variability in the surgical techniques and the involvement of different surgeons might have affected the results, although it provides some advantages such as it might better reflect actual practice than when reporting data from a single surgeon or technique. Third, although AOFAS is the most used instrument, this tool has some limitations in assessing the impact of HV surgery on HRQoL in terms of validity, reliability, and responsiveness, which may impact the statistical power of our effect estimates. Finally, numerous factors may have influenced clinician- and patientrelated outcomes, such as type of surgery, surgeon skill, other associated forefoot diseases (lesser toe deformities, metatarsalgia), and comorbidities.

\section{Conclusions}


In conclusion, our data confirmed the improvements in the clinical and radiological outcomes after HV surgery, and provided some evidence of these improvements not depending on the type of surgery or on some potential confounding factors such as BMI, HVA, 1-2 IMA, and DMAA. In addition, our outcomes indicated the suitability of including PROMs (pain scales, general QoL, and region-specific scales) as important outcomes in the assessment of HV surgery, since they are probably more important for the patient than the purely radiological findings.

\section{Abbreviations}

HV: Hallux Valgus; MTPJ: Metatarsophalangeal Joint; IMA: Intermetatarsal Angle; HRQoL: Health-Related Quality of Life; MIS: Minimally Invasive Surgery; AOFAS; American Orthopedic Foot and Ankle Society; PROMs: Patient-Reported Outcome Measures; BMI: Body Mass Index; DMAA: Distal Metatarsal Articular Angle; HMI: Hallux Metatarsophalangeal-Interphalangeal; VAS: Visual Analogue Scale; MOXFQ: Manchester-Oxford Foot Questionnaire; SF-12: Short Form health survey; EQ-5D: European Quality of Life-5 Dimensions; PCS: Physical Component Summay; MCS: Mental Component Summary; SD: Standard Deviation; ES: Effect Size.

\section{Declarations}

\section{Ethics approval and consent to participate}

The need for ethics committee approval was waived. All patients provided informed consent.

\section{Consent for publication}

Not applicable.

\section{Availability of data and materials}

Anonymised datasets can be made available on reasonable request to the corresponding author.

\section{Competing interests}

No author has any competing interests to declare.

\section{Funding}

This work did not receive any funding.

Authors' contributions

Study conception and design: LEHC, CAB, MGM, MAG, JLQR; Acquisition of data: LEHC, MAG, JLRQ; analysis and interpretation of data: $L E H C, C A B, V M V, M G M$; drafting of the manuscript: $L E H C, C A B, V M V, M G M$; Critical revision for important intellectual content: LEHC, VMV, CAB, JLQR, MAG, MGM; final approval of the version to be published: LEHC, VMV, CAB, JLQR, MAG, MGM. All authors participated sufficiently in the work to take public responsibility for appropriate portions of the content; and agree to be accountable for all aspects of the work

\section{Acknowledgements}

To the patients of the Virgen de la Luz Hospital in Cuenca (Spain) and the Health and Social Research Center, Universidad de Castilla La Mancha, Cuenca.

\section{References}


1. Nix S, Smith M, Vicenzino B. Prevalence of hallux valgus in the general population: a systematic review and metaanalysis. J Foot Ankle Res. 2010;3(1):21.

2. Mann RA, Coughlin MJ. Hallux valgus: etiology, anatomy, treatment and surgical considerations. Clin Orthop Relat Res. 1981;(157):31-41.

3. Nix SE, Vicenzino BT, Collins NJ, Smith MD. Characteristics of foot structure and footwear associated with hallux valgus: a systematic review. Osteoarthr Cartil. 2012;20(10):1059-74.

4. Viladot Voegeli A, Viladot Pericé A. Síndrome de insuficiencia del primer radio. En: Núñez-Samper Pizarroso M, Llanos Alcázar LF. Biomecánica, medicina y cirugía del pie. Barcelona: Masson; 2007. pp. 235-48.

5. Maffulli N, Oliva F, Coppola C et al. Minimally invasive hallux valgus correction: a technical note and a feasibility study. J Surg Orthop Adv 2005;14:193-8.

6. Myerson MS. Hallux valgus. Foot and ankle disorders. Philadelphia: WB Saunders. 2000; 213-89

7. Roddy E, Zhang W, Doherty M. Prevalence and associations of hallux valgus in a primary care population. Arthritis Rheum 59(6):857-862, 2008.

8. Saro C, Jensen I, Lindgren U, Fellander-Tsai L. Quality-of-life outcome after hallux valgus surgery. Quality Life Res 16(5):731-738, 2007.

9. Tai CC, Ridgeway S, Ramachandran M, et al. Patient expectations for hallux valgus surgery. J Orthop Surg (Hong Kong).2008;16(1):91-95

10. Menz HB,Roddy E,ThomasE, Croft PR.Impact of hallux valgus severityon general and foot-specific health-related quality of life. Arthritis Care Res 63(3):396-404, 2011.

11. Abhishek A, Roddy E, Zhang W, Doherty M. Are hallux valgus and big toe pain associated with impaired quality of life? A cross-sectional study. Osteoarthr Cartil. 2010;18(7):923-6.

12. Nix SE, Vicenzino BT, Smith MD. Foot pain and functional limitation in healthy adults with hallux valgus: a crosssectional study. BMC Musculoskelet Disord. 2012 Oct 16;13:197.

13. Golightly YM, Hannan MT, Dufour AB, Renner JB, Jordan JM. Factors associated with hallux valgus in a communitybased cross-sectional study of adults with and without osteoarthritis. Arthritis Care Res (Hoboken). 2015 May;67(6):7918.

14. Easley ME, Trnka HJ. Current concepts review: hallux valgus part II: operative treatment. Foot Ankle Int. 2007 Jun;28(6):748-58.

15. Deenik AR, Pilot P, Brandt SE, et al. Scarf versus chevron osteotomy in hallux valgus: a randomized controlled trial in 96 patients. Foot Ankle Int 2007;28(5):537-41

16. Robinson AH, Limbers JP. Modern concepts in the treatment of hallux valgus. J Bone Joint Surg Br 2005;87(8):1038-45.

17. Pichierri P, Sicchiero P, Fioruzzi A, Maniscalco P. Percutaneous hallux valgus surgery: strengths and weakness in our clinical experience. Acta Biomed 85(suppl2):121-125, 2014.

18. Hardy RH, Clapham JCR. Observations on hallux valgus. J Bone Joint Surg 33B:376-391, 1951.

19. Magnan B, Pezze L, Rossi N, et al. Percutaneous distal metatarsal osteotomy for correction of hallux valgus. J Bone Joint Surg Am. 2005; 87:1191-9.

20. Ma Q, Liang X, Lu J. Chevron osteotomy versus scarf osteotomy for hallux valgus correction: A meta-analysis. Foot Ankle Surg. 2019 Dec;25(6):755-760.

21. Smith SE, Landorf KB, Butterworth PA, Menz HB Scarf versus Chevron Osteotomy for the Correction of 1-2 Intermetatarsal Angle in Hallux Valgus: A Systematic Review and Meta-analysis. J Foot Ankle Surg. 2012 JulAug;51(4):437-44.

22. Yammine K, Assi C. A meta-analysis of comparative clinical studies of isolated osteotomy versus osteotomy with lateral soft tissue release in treating hallux valgus. Foot Ankle Surg. 2019 Oct;25(5):684-690. 
23. BauerT, De-Lavigne C, Biau D, De-Prado M, Isham S, Laffenétre Percutaneous hallux valgus surgery: aprospective multicenter study of 189 cases. Orthop Clin N Am 40:505-514

24. Bia A, Guerra-Pinto F, Pereira BS, Corte-Real N, Oliva XM. Percutaneous Osteotomies in Hallux Valgus: A Systematic Review. J Foot Ankle Surg. 2018 Jan - Feb;57(1):123-130

25. Malagelada F, Sahirad C, Dalmau-Pastor M, Vega J, Bhumbra R, Manzanares-Céspedes MC, Laffenêtre O. Minimally invasive surgery for hallux valgus: a systematic review of current surgical techniques. Int Orthop. 2019 Mar;43(3):625637.

26. Kaufmann G, Dammerer D, Heyenbrock F, Braito M, Moertlbauer L, Liebensteiner M. Minimally invasive versus open chevron osteotomy for hallux valgus correction: a randomized controlled trial. Int Orthop. 2019 Feb;43(2):343-350

27. Lee M, Walsh J, Smith MM, Ling J, Wines A, Lam P. Hallux Valgus Correction Comparing Percutaneous Chevron/Akin (PECA) and Open Scarf/Akin Osteotomies. Foot Ankle Int. 2017 Aug;38(8):838-846.

28. Stith A, Dang D, Griffin M, Flint W, Hirose C, Coughlin M. Rigid Internal Fixation of Proximal Crescentic Metatarsal Osteotomy in Hallux Valgus Correction. Foot Ankle Int. 2019 Jul;40(7):778-789.

29. Nilsdotter AK, Cöster ME, Bremander A, Cöster MC. Patient-reported outcome after hallux valgus surgery - a two year follow up. Foot Ankle Surg. 2019 Aug;25(4):478-481.

30. Hunt KJ, Hurwit D. Use of patient-reported outcome measures in foot and ankle research. J Bone Joint Surg Am 2013;95(16):e1181-89.

31. Schrier JC, Palmen LN, Verheyen CC, Jansen J, Koëter S. Patient-reported outcome measures in hallux valgus surgery. A review of literature. Foot Ankle Surg. 2015 Mar;21(1):11-5.

32. Klugarova J, Hood V, Bath-Hextall F, Klugar M, Mareckova J, Kelnarova Z. Effectiveness of surgery for adults with hallux valgus deformity: a systematic review. JBI Database System Rev Implement Rep. 2017;15(6):1671-1710.

33. Hernández-Castillejo LE, Martínez Vizcaíno V, Garrido-Miguel M, Cavero-Redondo I, Pozuelo-Carrascosa DP, Álvarez-Bueno C. Effectiveness of hallux valgus surgery on patient quality of life: a systematic review and meta-analysis. Acta Orthop. 2020 Aug;91(4):450-456.

34. Barg A, Harmer JR, Presson AP, Zhang C, Lackey M, Saltzman CL. Unfavorable Outcomes Following Surgical Treatment of Hallux Valgus Deformity: A Systematic Literature Review. J Bone Joint Surg Am. 2018 Sep 19;100(18):1563-1573.

35. World Medical Association declaration of Helsinki. Recommendations guiding physicians in biomedical research involving human subjects. JAMA. 1997;277(11):925-926.

36. Kernozek TW, Sterriker SA. Chevron (Austin) distal metatarsal osteotomy for hallux valgus: comparison of pre- and postsurgical characteristics. Foot Ankle Int 2002;23:503-8.

37. Trnka H-J. The scarf osteotomy. Instructional Course lecture $N^{\circ} 326$, techniques in hallux valgus surgery. $72 n d$ Annual Meeting AAOS 2005.

38. Isham SA. The Reverdin-Isham Procedure for the Correction of Hallux Abducto Valgus. A Distal Metatarsal Osteotomy Procedure. Clin Podiatr Med Surg. 1991 Jan;8(1):81-94.

39. Coughlin MJ, Saltzman CL, Anderson RB: Surgery of the foot andankle. 9.a ed. Philadelphia: Elsevier Inc; 2009.

40. KaufmannG, HandleM, LiebensteinerM, Braito M, Dammerer Percutaneous Minimally Invasive Akin Osteotomy in Hallux Valgus Interphalangeus: A Case Series. Int Orthop. 2018 Jan;42(1):117-124.

41. Kitaoka HB, Alexander IJ, Adelaar RS, et al. Clinical rating systems for the ankle hindfoot, midfoot, hallux, lesser toes. Foot Ankle Int 1994;15:349-353.

42. Myles PS, Troedel S, Boquest M, Reeves M. The pain visual analog scale: is it linear or nonlinear? Anesth Analg. 1999;89(6):1517-1520.

43. Garcés JB, Winson I, Goldhahn S, Castro MD, Swords MP, Grujic L, Rammelt S, Sands AK. Reliability, validity and responsiveness of the Spanish Manchester-Oxford Foot Questionnaire (MOXFQ) in patients with foot or ankle surgery. 2016 Mar;22(1):59-70. 
44. Vilagut G, Valderas JM, Ferrer M, Garin O, López-García E, Alonso J. Interpretation of SF-36 and SF-12 questionnaires in Spain: physical and mental components. Med Clin (Barc). 2008 May 24;130(19):726-35.

45. Badia X, Roset M, Montserrat S, Herdman M, Segura A. The Spanish version of EuroQol: a description and its applications. European Quality of Life scale. Med Clin (Barc). 1999;112 Suppl 1:79-85.

46. Baumhauer JF, Nawoczenski DA, DiGiovanni BF, Wilding GE. Reliability and validity of the American Orthopaedic Foot and Ankle Society Clinical Rating Scale: a pilot study for the hallux and lesser toes. Foot Ankle Int. 2006;27:1014-1019.

47. Morley D, Jenkinson C, Doll H, Lavis G, Sharp R, Cooke P, et al. The Manchester- Oxford Foot Questionnaire (MOXFQ): Development and validation of a summary index score. Bone Joint Res 2013;2:66-9.

48. Ware J Jr, Kosinski M, Keller SD. A 12-Item Short-Form Health Survey: construction of scales and preliminary tests of reliability and validity. Med Care. Med Care. 1996;34(3):220-33.

49. Ramos-Goñi JM, Craig BM, Oppe M, et al. Handling data quality issues to estimate the Spanish EQ-5D-5L value set using a hybrid interval regression approach. Value Health. 2018;21(5):596-604.

50. Panchbhavi VK, Trevino S. Comparison between manual and computer-assisted measurements of hallux valgus parameters. Foot Ankle Int. 2004;25:708-711.

51. Jones S, Al Hussainy HA, Ali F, Betts RP, Flowers MJ. Scarf osteotomy for hallux valgus: a prospective clinical and pedobarographic study. J Bone Joint Surg Br. 2004;86:830-836.

52. Schneider W, Csepan R, Knahr K. Reproducibility of the radiographic metatarsophalangeal angle in hallux surgery. $J$ Bone Joint Surg [Am] 2003;85-A:949-9.

53. Cohen J. Statistical power analysis for the behavioral sciences. Rev. ed. New York, NY: Academic Press; 1977.

54. Coetzee JC. Scarf osteotomy for hallux valgus repair: the dark side. Foot Ankle Int. 2003 Jan;24(1):29-33.

55. Kaptan AY, Çavuşoğlu AT, Tokgöz MA, Elma T, Yapar A. Distal oblique metatarsal osteotomy technique in hallux valgus deformity: Clinical and radiological results. Jt Dis Relat Surg. 2020;31(1):88-94.

56. Verdu-Roman C, Sanz-Reig J, Martinez-Gimenez E, et al. Plantar pressure improvement in moderate hallux valgus with modified chevron osteotomy: Clinical and radiographic outcomes. Foot Ankle Surg. 2020;26(2):205-208.

57. Young KW, Lee HS, Park SC. Modified Proximal Scarf Osteotomy for Hallux Valgus. Clin Orthop Surg. 2018;10(4):479-483.

58. Schneider W, Knahr K. Poor agreement between prospective and retrospective assessment of hallux surgery using the AOFAS Hallux Scale. Foot Ankle Int. 2005 Dec;26(12):1062-6.

59. Ibrahim T, Beiri A, Azzabi M, Best AJ, Taylor GJ, Menon DK. Reliability and validity of the subjective component of the American Orthopaedic Foot and Ankle Society clinical rating scales. J Foot Ankle Surg 46:65-74, 2007.

60. Lucas y Hernandez J, Golanó P, Roshan-Zamir S, Darcel V, Chauveaux D, Laffenêtre O. Treatment of moderate hallux valgus by percutaneous, extra-articular reverse-L Chevron (PERC) osteotomy. Bone Joint J. 2016;98-B(3):365-373.

61. Bock P, Kluger R, Kristen KH, Mittlböck M, Schuh R, Trnka HJ. The Scarf Osteotomy with Minimally Invasive Lateral Release for Treatment of Hallux Valgus Deformity: Intermediate and Long-Term Results. J Bone Joint Surg Am. 2015;97(15):1238-1245.

62. Milczarek MA, Milczarek JJ, Tomasik B, Łaganowski P, Nowak K, Dom zalski M. Being overweight has limited effect on SCARF osteotomy outcome for hallux valgus correction. Int Orthop 2017;41:765-72.

63. Castioni D, Fanelli D, Gasparini G, lannò B, Galasso O. Scarf osteotomy for the treatment of moderate to severe hallux valgus: Analysis of predictors for midterm outcomes and recurrence. Foot Ankle Surg. 2020;26(4):439-444.

64. Chen JY, Lee MJ, Rikhraj K, et al. Effect of Obesity on Outcome of Hallux Valgus Surgery. Foot Ankle Int. 2015;36(9):10781083.

65. Di Giorgio L, Touloupakis G, Simone S, Imparato L, Sodano L, Villani C. The Endolog system for moderate-to-severe hallux valgus. J Orthop Surg (Hong Kong). 2013;21(1):47-50.

66. Ohzawa S, Kubota M. Proximal oblique metatarsal osteotomy for hallux valgus using a plantar locking plate. Foot Ankle Surg. 2018 Dec;24(6):501-505. 
67. Chiang CC, Lin CF, Tzeng YH, Huang CK, Chen WM, Liu CL. Distal linear osteotomy compared to oblique diaphyseal osteotomy in moderate to severe hallux valgus. Foot Ankle Int. 2012;33(6):479-486.

68. Aminian A, Kelikian A, Moen T. Scarf osteotomy for hallux valgus deformity: an intermediate followup of clinical and radiographic outcomes. Foot Ankle Int. 2006;27(11):883-886.

69. Okuda R, Kinoshita M, Yasuda T, Jotoku T, Kitano N, Shima H. Postoperative incomplete reduction of the sesamoids as a risk factor for recurrence of hallux valgus. J Bone Joint Surg Am. 2009;91(7):1637-1645.

70. Pentikainen I, Ojala R, Ohtonen P, Piippo J, Leppilahti J. Preoperative radiological factors correlated to long-term recurrence of hallux valgus following distal chevron osteotomy. Foot Ankle Int. 2014;35(12):1262-1267.

71. Raikin SM, Miller AG, Daniel J. Recurrence of hallux valgus: a review. Foot Ankle Clin. 2014;19(2):259-274.

72. Deenik AR, de Visser E, Louwerens JW, de Waal Malefijt M, Draijer FF, de Bie RA. Hallux valgus angle as main predictor for correction of hallux valgus. BMC Musculoskelet Disord. 2008;9:70.

73. Magnan B, Negri S, Maluta T, Dall'Oca C, Samaila E.Minimally invasive distal first metatarsal osteotomy can be an option for recurrent hallux valgus. Foot Ankle Surg.2019;25(3):332-339.

\section{Tables}

Table 1. Characteristics of the case series ( $n=72$ cases in 72 patients) 


\begin{tabular}{|c|c|}
\hline Variable & Mean \\
\hline Age (years) & $59.67 \pm 11.39$ \\
\hline Female n, (\%) & $70(97.2)$ \\
\hline Weight (Kg) & $68.53 \pm 9.01$ \\
\hline Height (cm) & $158.48 \pm 6.79$ \\
\hline $\mathrm{BMI}\left(\mathrm{Kg} / \mathrm{m}^{2}\right)$ & $27.35 \pm 3.86$ \\
\hline Normal weight $\mathrm{n},(\%)$ & $21(29.2)$ \\
\hline Overweight n, (\%) & $32(44.4)$ \\
\hline Obesity n, (\%) & $19(26.4)$ \\
\hline \multicolumn{2}{|l|}{ Side } \\
\hline Right n, (\%) & $38(52.8)$ \\
\hline Left n, (\%) & $34(47.2)$ \\
\hline \multicolumn{2}{|l|}{ Indication for surgery } \\
\hline Pain, n (\%) & $15(20.8)$ \\
\hline Shoe fit problems, n (\%) & $2(2.8)$ \\
\hline Pain and shoe fit problems, $\mathrm{n}(\%)$ & $55(76.4)$ \\
\hline Family history, $n(\%)$ & $62(86.1)$ \\
\hline Maternal inheritance, n (\%) & $42(58.3)$ \\
\hline Paternal inheritance, n (\%) & $20(27.8)$ \\
\hline Metatarsalgia, n (\%) & $23(31.9)$ \\
\hline Lesser toe deformities, n (\%) & $13(18.1)$ \\
\hline \multicolumn{2}{|l|}{ Metatarsal formula } \\
\hline Index minus, $\mathrm{n}(\%)$ & $56(77.8)$ \\
\hline Index plus, n (\%) & $1(1.4)$ \\
\hline Index minus plus, n (\%) & $15(20.8)$ \\
\hline Egyptian foot, n (\%) & $57(79.2)$ \\
\hline \multicolumn{2}{|l|}{ Hallux rigidus } \\
\hline Grade 1, n (\%) & $9(12.5)$ \\
\hline Grade 2, n (\%) & $4(5.6)$ \\
\hline Follow-up (months) & $17.68 \pm 3.11$ \\
\hline
\end{tabular}

Results are shown as mean and $( \pm)$ Standard deviation. For categorical variables the values are expressed in percentages. Abbreviation: BMI, body mass index. 
Table 2. Mean differences of the preoperative and end of follow-up clinical and radiological outcomes.

\begin{tabular}{|c|c|c|c|c|c|}
\hline Outcomes & $\begin{array}{l}\text { Preoperative } \\
\text { n (72) }\end{array}$ & $\begin{array}{l}\text { End of follow-up } \\
n(72)\end{array}$ & $\Delta$ Crude change & $95 \% \mathrm{Cl}$ & $\mathrm{ES} *$ \\
\hline \multicolumn{6}{|l|}{ Clinical } \\
\hline \multicolumn{6}{|l|}{$V A S^{b}$} \\
\hline Total & $5.01 \pm 1.26$ & $1.26 \pm 0.96$ & -3.75 & $(-4.01$ to -3.49$)$ & 3.347 \\
\hline \multicolumn{6}{|l|}{$A O F A S^{a}$} \\
\hline Total & $42.16 \pm 10.11$ & $83.31 \pm 6.23$ & 41.15 & (38.72 to 43.58$)$ & 4.900 \\
\hline Pain & $14.17 \pm 9.15$ & $33.19 \pm 4.69$ & 19.02 & (17.01 to 21.04$)$ & 2.616 \\
\hline Function & $27.22 \pm 3.90$ & $37.94 \pm 2.78$ & 10.72 & (9.55 to 11.89 ) & 3.165 \\
\hline Alignment & $0.78 \pm 2.38$ & $12.18 \pm 3.45$ & 11.40 & (10.54 to 12.25$)$ & 3.846 \\
\hline \multicolumn{6}{|l|}{$M O X F Q^{b}$} \\
\hline Total & $61.44 \pm 7.09$ & $12.35 \pm 4.85$ & -49.08 & $(-50.73$ to -47.43$)$ & 8.081 \\
\hline Pain & $69.31 \pm 12.31$ & $10.76 \pm 6.80$ & -58.54 & $(-61.16$ to -55.91$)$ & 5.887 \\
\hline Walking & $62.24 \pm 7.85$ & $15.04 \pm 7.42$ & -47.21 & $(-49.81$ to -44.60$)$ & 6.179 \\
\hline Social & $50.61 \pm 12.46$ & $10.07 \pm 5.40$ & -40.53 & $(-43.21$ to -37.86$)$ & 4.221 \\
\hline \multicolumn{6}{|l|}{$S F-12^{a}$} \\
\hline PCS & $36.26 \pm 5.32$ & $47.06 \pm 4.82$ & 10.79 & (9.55 to 12.03 ) & 2.127 \\
\hline MCS & $38.23 \pm 8.04$ & $46.49 \pm 4.16$ & 8.25 & (6.49 to 10.01$)$ & 1.290 \\
\hline \multicolumn{6}{|l|}{$E Q-5 D^{a}$} \\
\hline Total & $0.64 \pm 0.08$ & $0.90 \pm 0.10$ & 0.26 & (0.23 to 0.28$)$ & 2.871 \\
\hline \multicolumn{6}{|c|}{ Radiological $^{c}$} \\
\hline HVA & $30.80^{\circ} \pm 3.56$ & $10.22^{\circ} \pm 1.01$ & -20.58 & $(-21.32$ to -19.83$)$ & 7.865 \\
\hline 1-2 IMA & $12.31^{\circ} \pm 1.60$ & $7.71^{\circ} \pm 0.86$ & -4.59 & $(-5.08$ to -4.11$)$ & 3.581 \\
\hline DMAA & $13.44^{\circ} \pm 0.88$ & $7.55^{\circ} \pm 0.99$ & -5.88 & $(-6.18$ to -5.59$)$ & 6.288 \\
\hline
\end{tabular}

Results are shown as mean and $( \pm)$ Standard deviation. Bold values indicate statistical significance $p \leq 0.05$.

Abbreviations: VAS,visual analogue scale; AOFAS,American Orthopaedic Foot and Ankle Society; MOXFQ, Manchester-Oxford Foot Questionnaire; SF-12,Short Form-12 Health Survey; PCS, Physical Component Score; MCS, Mental Component, Score; EQ5D, EuroQol-5D; HVA, hallux valgus angle; 1-2 IMA, 1-2 intermetatarsal angle; DMAA, distal metatarsal articular angle; MTPJ, metatarsophalangeal joint; ES, effect size.

${ }^{a}$ Higher scores indicate a better health-related quality of life.

${ }^{b}$ Lower scores indicate a better health-related quality of life.

${ }^{\mathrm{c}}$ Lower scores indicate a better radiological outcome. 
P values for all comparisons between preoperative and end of follow-up were statistical significance $p \leq 0.001$.

*The size of the effect was categorized as 0.2 (considered a weak effect), 0.5 (considered a moderate effect), 0.8 (considered a strong effect), and $>1.0$ (considered a very strong effect) by Cohen.

Table 3. Pre-post mean differences on the clinical outcomes by types of surgery, controlling for baseline outcome (model 1) and baseline outcome, age, body mass index, hallux valgus angle, 1-2 intermetatarsal angle and distal metatarsal articular angle(model 2). 


\begin{tabular}{|c|c|c|c|c|c|c|c|}
\hline & & \multicolumn{2}{|c|}{$\begin{array}{l}\text { Chevron osteotomy } \\
\text { n (16) }\end{array}$} & \multicolumn{2}{|c|}{$\begin{array}{l}\text { Scarf osteotomy } \\
\text { n (24) }\end{array}$} & \multicolumn{2}{|c|}{$\begin{array}{l}\text { Percutaneous surgery } \\
\text { n (32) }\end{array}$} \\
\hline VAS $^{b}$ & & Model 1 & Model 2 & Model 1 & Model 2 & Model 1 & Model 2 \\
\hline \multirow[t]{3}{*}{ Total } & Preoperative & $5.18 \pm 1.37$ & $5.19 \pm 1.37$ & $5.00 \pm 1.18$ & $5.00 \pm 1.18$ & $4.94 \pm 1.29$ & $4.93 \pm 1.29$ \\
\hline & $\begin{array}{l}\text { End-of } \\
\text { follow up }\end{array}$ & $1.37 \pm 0.95$ & $1.37 \pm 0.95$ & $1.50 \pm 0.83$ & $1.50 \pm 0.83$ & $1.03 \pm 1.03$ & $1.03 \pm 1.04$ \\
\hline & ES & 3.23 & 3.24 & 3.43 & 3.43 & 3.35 & 3.34 \\
\hline \multicolumn{8}{|l|}{ AOFAS $^{a}$} \\
\hline \multirow[t]{3}{*}{ Total } & Preoperative & $41.68 \pm 10.90$ & $41.69 \pm 10.99$ & $41.45 \pm 10.44$ & $41.56 \pm 10.44$ & $42.93 \pm 9.71$ & $42.94 \pm 9.70$ \\
\hline & $\begin{array}{l}\text { End-of } \\
\text { follow up }\end{array}$ & $84.31 \pm 5.53$ & $84.31 \pm 5.54$ & $82.00 \pm 5.90$ & $82.03 \pm 5.90$ & $83.81 \pm 6.80$ & $83.81 \pm 6.81$ \\
\hline & ES & 4.93 & 4.93 & 4.60 & 4.59 & 4.87 & 4.87 \\
\hline \multirow[t]{3}{*}{ Pain } & Preoperative & $12.50 \pm 10.00$ & $12.50 \pm 10.03$ & $15.00 \pm 8.84$ & $15.01 \pm 8.84$ & $14.37 \pm 9.13$ & $14.38 \pm 9.13$ \\
\hline & $\begin{array}{l}\text { End-of } \\
\text { follow up }\end{array}$ & $33.12 \pm 4.78$ & $33.12 \pm 4.79$ & $31.66 \pm 3.80$ & $31.67 \pm 3.80$ & $34.37 \pm 5.04$ & $34.37 \pm 5.04$ \\
\hline & ES & 2.63 & 2.63 & 2.44 & 2.44 & 2.71 & 2.71 \\
\hline \multirow[t]{3}{*}{ Function } & Preoperative & $28.68 \pm 3.77$ & $28.69 \pm 3.77$ & $26.12 \pm 3.98$ & $26.12 \pm 3.99$ & $27.31 \pm 3.78$ & $27.32 \pm 3.78$ \\
\hline & $\begin{array}{l}\text { End-of } \\
\text { follow up }\end{array}$ & $37.50 \pm 2.44$ & $37.50 \pm 2.44$ & $38.54 \pm 2.82$ & $38.54 \pm 2.83$ & $37.71 \pm 2.91$ & $37.72 \pm 2.90$ \\
\hline & ES & 2.77 & 2.77 & 3.60 & 3.60 & 3.1 & 3.1 \\
\hline \multirow{3}{*}{ Alignment } & Preoperative & $0.50 \pm 2.00$ & $0.50 \pm 2.01$ & $0.33 \pm 1.63$ & $0.32 \pm 1.62$ & $1.25 \pm 2.95$ & $1.25 \pm 2.95$ \\
\hline & $\begin{array}{l}\text { End-of } \\
\text { follow up }\end{array}$ & $13.68 \pm 2.82$ & $13.69 \pm 2.80$ & $11.79 \pm 3.56$ & $11.80 \pm 3.56$ & $11.71 \pm 3.54$ & $11.72 \pm 3.54$ \\
\hline & ES & 5.40 & 5.38 & 4.14 & 4.15 & 3.21 & 3.21 \\
\hline \multicolumn{8}{|l|}{ MOXFQ ${ }^{b}$} \\
\hline \multirow[t]{3}{*}{ Total } & Preoperative & $60.71 \pm 7.95$ & $60.71 \pm 7.95$ & $62.40 \pm 7.72$ & $62.40 \pm 7.71$ & $61.08 \pm 6.27$ & $61.10 \pm 6.27$ \\
\hline & $\begin{array}{l}\text { End-of } \\
\text { follow up }\end{array}$ & $12.30 \pm 4.63$ & $12.30 \pm 4.62$ & $12.88 \pm 5.17$ & $12.89 \pm 5.17$ & $11.99 \pm 4.84$ & $12.00 \pm 4.84$ \\
\hline & ES & 7.44 & 7.44 & 7.53 & 7.53 & 8.76 & 8.76 \\
\hline \multirow[t]{3}{*}{ Pain } & Preoperative & $69.68 \pm 12.97$ & $69.69 \pm 12.98$ & $69.79 \pm 12.46$ & $69.80 \pm 12.45$ & $68.75 \pm 12.24$ & $68.75 \pm 12.24$ \\
\hline & $\begin{array}{l}\text { End-of } \\
\text { follow up }\end{array}$ & $11.25 \pm 5.62$ & $11.25 \pm 5.62$ & $12.08 \pm 5.69$ & $12.09 \pm 5.70$ & $9.53 \pm 7.96$ & $9.54 \pm 7.97$ \\
\hline & ES & 5.84 & 5.84 & 5.96 & 5.96 & 5.73 & 5.73 \\
\hline \multirow[t]{3}{*}{ Walking } & Preoperative & $60.22 \pm 8.84$ & $60.21 \pm 8.84$ & $64.40 \pm 8.12$ & $64.40 \pm 8.09$ & $61.64 \pm 6.95$ & $61.65 \pm 6.93$ \\
\hline & $\begin{array}{l}\text { End-of } \\
\text { follow up }\end{array}$ & $15.80 \pm 6.78$ & $15.80 \pm 6.78$ & $14.84 \pm 7.71$ & $14.85 \pm 7.70$ & $14.80 \pm 7.71$ & $14.80 \pm 7.72$ \\
\hline & ES & 5.63 & 5.63 & 6.25 & 6.27 & 6.38 & 6.38 \\
\hline Social & Preoperative & $50.78 \pm 11.60$ & $50.79 \pm 11.60$ & $50.00 \pm 11.36$ & $50.00 \pm 11.35$ & $50.97 \pm 13.94$ & $50.97 \pm 13.94$ \\
\hline
\end{tabular}




\begin{tabular}{|c|c|c|c|c|c|c|c|}
\hline & $\begin{array}{l}\text { End-of } \\
\text { follow up }\end{array}$ & $7.81 \pm 2.79$ & $7.82 \pm 2.80$ & $10.67 \pm 5.67$ & $10.68 \pm 5.67$ & $10.74 \pm 5.98$ & $10.74 \pm 5.98$ \\
\hline & ES & 5.10 & 5.10 & 4.38 & 4.38 & 3.75 & 3.75 \\
\hline \multicolumn{8}{|c|}{ SF-12 ${ }^{a}$} \\
\hline \multirow[t]{3}{*}{ PCS } & Preoperative & $36.33 \pm 5.29$ & $36.33 \pm 5.30$ & $35.27 \pm 4.69$ & $35.28 \pm 4.71$ & $36.98 \pm 5.81$ & $36.98 \pm 5.80$ \\
\hline & $\begin{array}{l}\text { End-of } \\
\text { follow up }\end{array}$ & $47.37 \pm 4.84$ & $47.38 \pm 4.83$ & $44.63 \pm 4.26$ & $44.63 \pm 4.26$ & $48.70 \pm 4.60$ & $48.70 \pm 4.60$ \\
\hline & $\mathrm{ES}$ & 2.18 & 2.18 & 2.10 & 2.10 & 2.23 & 2.23 \\
\hline \multirow[t]{3}{*}{ MSC } & Preoperative & $38.37 \pm 9.43$ & $38.37 \pm 9.43$ & $38.83 \pm 6.54$ & $38.84 \pm 6.54$ & $37.71 \pm 8.53$ & $37.71 \pm 8.52$ \\
\hline & $\begin{array}{l}\text { End-of } \\
\text { follow up }\end{array}$ & $45.56 \pm 2.94$ & $45.56 \pm 2.93$ & $47.51 \pm 3.83$ & $47.52 \pm 3.82$ & $46.18 \pm 4.81$ & $46.18 \pm 4.80$ \\
\hline & ES & 1.02 & 1.02 & 1.61 & 1.61 & 1.22 & 1.22 \\
\hline \multicolumn{8}{|l|}{$E Q-5^{a}$} \\
\hline \multirow[t]{3}{*}{ Total } & Preoperative & $0.66 \pm 0.09$ & $0.66 \pm 0.09$ & $0.62 \pm 0.06$ & $0.62 \pm 0.06$ & $0.65 \pm 0.07$ & $0.65 \pm 0.07$ \\
\hline & $\begin{array}{l}\text { End-of } \\
\text { follow up }\end{array}$ & $0.91 \pm 0.09$ & $0.90 \pm 0.09$ & $0.88 \pm 0.09$ & $0.89 \pm 0.09$ & $0.90 \pm 0.11$ & $0.90 \pm 0.10$ \\
\hline & ES & 2.77 & 2.77 & 3.40 & 3.40 & 2.90 & 2.90 \\
\hline
\end{tabular}

Results are shown as mean and $( \pm)$ Standard deviation. Bold values indicate statistical significance $p \leq 0.05$

Abbreviations: VAS,visual analogue scale; AOFAS,American Orthopaedic Foot and Ankle Society; MOXFQ, Manchester-Oxford Foot Questionnaire; SF-12,Short Form-12 Health Survey; PCS, Physical Component Score; MCS, Mental Component, Score; EQ5D, EuroQol-5D; ES, effect size.

${ }^{a}$ Higher scores indicate a better health-related quality of life ${ }^{b}$ Lower scores indicate a better health-related quality of life. $\mathrm{P}$ values for all comparisons between preoperative and end of follow-up were statistical significance $p \leq 0.001$. * The size of the effect was categorized as 0.2 (considered a weak effect), 0.5 (considered a moderate effect), 0.8 (considered a strong effect), and >1.0 (considered a very strong effect) by Cohen. Model 1: adjusted by baseline outcome; Model 2: adjusted by baseline outcome, age, body mass index, hallux valgus angle, 1-2 intermetatarsal angle and distal metatarsal articular angle.

Table 4. Pre-post mean differences on the radiological outcomes by types of surgery, controlling for baseline outcome (model 1) and baseline outcome, age, body mass index, hallux valgus angle, 1-2 intermetatarsal angle and distal metatarsal articular angle (model 2). 


\begin{tabular}{|c|c|c|c|c|c|c|c|}
\hline \multirow[b]{2}{*}{$\mathrm{HVA}^{\mathrm{a}}$} & & \multicolumn{2}{|c|}{$\begin{array}{l}\text { Chevron osteotomy } \\
\mathrm{n}(16)\end{array}$} & \multicolumn{2}{|c|}{$\begin{array}{l}\text { Scarf osteotomy } \\
\text { n (24) }\end{array}$} & \multicolumn{2}{|c|}{$\begin{array}{l}\text { Percutaneous surgery } \\
\mathrm{n}(32)\end{array}$} \\
\hline & & Model 1 & Model 2 & Model 1 & Model 2 & Model 1 & Model 2 \\
\hline & Preoperative & $31.44 \pm 3.34$ & $31.43 \pm 3.34$ & $32.21 \pm 3.55$ & $32.21 \pm 3.55$ & $29.44 \pm 3.26$ & $29.43 \pm 3.27$ \\
\hline & End-of follow up & $10.32 \pm 1.08$ & $10.31 \pm 1.07$ & $9.91 \pm 0.92$ & $9.91 \pm 0.92$ & $10.41 \pm 1.01$ & $10.40 \pm 1.01$ \\
\hline & ES & 8.50 & 8.50 & 8.60 & 8.60 & 7.88 & 7.86 \\
\hline \multicolumn{8}{|c|}{ 1-2 IMA } \\
\hline & Preoperative & $12.00 \pm 0.96$ & $12.00 \pm 0.96$ & $14.00 \pm 1.35$ & $14.00 \pm 1.32$ & $11.18 \pm 0.78$ & $11.19 \pm 0.78$ \\
\hline & End-of follow up & $7.68 \pm 0.78$ & $7.69 \pm 0.78$ & $7.04 \pm 0.62$ & $7.04 \pm 0.62$ & $8.21 \pm 0.71$ & $8.22 \pm 0.71$ \\
\hline & ES & 4.93 & 4.92 & 6.62 & 6.74 & 3.98 & 3.98 \\
\hline \multicolumn{8}{|c|}{$\mathrm{DMAA}^{\mathrm{a}}$} \\
\hline & Preoperative & $13.68 \pm 0.96$ & $13.69 \pm 0.96$ & $13.62 \pm 0.96$ & $13.63 \pm 0.97$ & $13.19 \pm 0.73$ & $13.18 \pm 0.73$ \\
\hline & End-of follow up & $6.50 \pm 0.63$ & $6.50 \pm 0.63$ & $8.58 \pm 0.50$ & $8.53 \pm 0.51$ & $7.31 \pm 0.64$ & $7.31 \pm 0.64$ \\
\hline & ES & 8.84 & 8.85 & 6.58 & 6.58 & 8.56 & 8.55 \\
\hline
\end{tabular}

Results are shown as mean and $( \pm)$ Standard deviation. Bold values indicate statistical significance $p \leq 0.05$

Abbreviations: HVA, hallux valgus angle; 1-2 IMA, 1-2 intermetatarsal angle; DMAA, distal metatarsal articular angle; ES, effect size.

${ }^{a}$ Lower scores indicate a better radiological outcome.

$P$ values for all comparisons between preoperative and end of follow-up were statistical significance $p \leq 0.001$. * The size of the effect was categorized as 0.2 (considered a weak effect), 0.5 (considered a moderate effect), 0.8 (considered a strong effect), and >1.0 (considered a very strong effect) by Cohen. Model 1: adjusted by baseline outcome; Model 2: adjusted by baseline outcome, age, body mass index, hallux valgus angle, 1-2 intermetatarsal angle and distal metatarsal articular angle.

\section{Supplementary Files}

This is a list of supplementary files associated with this preprint. Click to download.

- Supplementarymaterial.docx 